\title{
What can a mother die of at the Parakou University Hospital Center in Africa?
}

\author{
Sosthene Adisso $^{1 *}$, Gisele-Estelle T. Agbossaga ${ }^{1}$, Mukanire Ntakwinja ${ }^{2}$
}

\author{
${ }^{1}$ Department of Obstetrics and Gynecology, University Clinic of Obstetrics and Gynecology, Cotonou \\ ${ }^{2}$ Panzi General Hospital, Bukavu, Democratic Republic of Congo
}

Received: 17 February 2018

Accepted: 19 March 2018

\section{*Correspondence:}

Dr. Sosthene Adisso,

E-mail: noudeli2014@gmail.com

Copyright: () the author(s), publisher and licensee Medip Academy. This is an open-access article distributed under the terms of the Creative Commons Attribution Non-Commercial License, which permits unrestricted non-commercial use, distribution, and reproduction in any medium, provided the original work is properly cited.

\section{ABSTRACT}

Background: Maternal mortality is a scourge that severely undermines Benin and affects its development. The fact is that despite the efforts that have been made for decades, the causes remain unchanged. What is the evolution of maternal deaths in the maternity CHUD of the Borgou-Alibori which serves the departments of the Borgou and the Alibori populated by 1,245,264 inhabitants? The objectives of the present study aim to assess the ratio of maternal deaths, profile of deceased women, causes of death.

Methods: This study took place at the maternity CHUD-B and covered a five-year period from January 1, 2010 to December 31, 2014. This is a retrospective, cross-sectional, analytical and descriptive study covering 113 cases of maternal death.

Results: During this period, we noted from 2010 to 2014 an evolution from 953 to 1388 deaths for 100,000 live births. The deceased women were for the most part illiterate, without any profession and married. The main direct causes of maternal deaths in order of frequency are hemorrhage $47.7 \%$, eclampsia $19.5 \%$, infection $9.8 \%$, dystocia $3.5 \%$. Indirect causes account for $19.5 \%$ of maternal deaths. The administration of emergency obstetric care has occurred under conditions where the third delay is found in $22.1 \%$ of cases with as the dominant factor the nonavailability of blood products.

Conclusions: In the face of these circumstances, it is necessary to revise the system of the management of the Gravido-puerperium in the peripheral formations and in the maternity of the CHUD-B and then the conditions of transfer in order to positively influence the reduction of the mortality Maternal.

Keywords: Direct and indirect Causes, Emergency obstetric care, Gravido-puerperium, Maternal mortality, Maternal deaths

\section{INTRODUCTION}

A maternal death means the death of a woman who occurred during the pregnancy or within 42 days after her termination, regardless of the duration and location for any cause determined or aggravated by the pregnancy or the care she has Motivated, but not accidental or fortuitous. ${ }^{1}$ Direct causes representing $80 \%$ of all maternal deaths are: hemorrhage, infection, abortion and high blood pressure. The indirect causes are for the most part: malaria and HIV on pregnancy. Maternal mortality in sub-saharan Africa remains the highest in the world in 2010, reaching 510 deaths for 100,000 live births. $^{2}$ Beyond this mortality burden, these deaths are the visible part of an important maternal morbidity that is still poorly known. 
The economic and social consequences of these deaths are important and are a hindrance to development. The Millennium Development Goals have increased investments and interventions in order to achieve a reduction in the maternal mortality ratio of $45 \%$ between 1990 and $2015 .^{3}$

These interventions focused on improving the quality of prenatal consultation, reducing the delay in the use of care, and promoting qualified assistance during childbirth through the improvement of the quality Emergency Obstetric Care (SOU).

These efforts combined with various parameters of global social development have led to a downward trend in maternal mortality in almost all countries of the world, including Benin. Thus from 1990 to 2010, the mortality ratio decreased from 770 to 350 deaths for 100,000 live births (NV). ${ }^{4}$

However, in 2015, the Millennium Development Goal 5 was not achieved. The mortality ratio remains high with 340 deaths for $100,000 \mathrm{NV}$ in $2013 .{ }^{4}$ In addition, there is an unfairness in the distribution of this maternal mortality burden between the different socio-economic strata and between the urban and rural areas of the country.

The persistence of high maternal mortality despite a proposal for institutional delivery of more than $80 \%$ suggests that a significant proportion of deaths occur in the care environment, thus constituting a bottleneck in the significant reduction in maternal mortality in Benin.

This study focuses on these maternal deaths occurring in the care environment in Benin and uses as a study framework the University Hospital of the North Benin region.

Specifically, this article presents the evolution of the ratio of maternal mortality in University Hospital of Parakou in Benin between 2010 and 2014, determines the demographic profile of deceased women, presents the distribution of the causes of Death of maternal deaths and discusses some assumptions about the qualities of the penny in hospitals in Benin.

\section{METHODS}

In this study, the operational definition of maternal death used is that based on the tenth International Classification of diseases.

It shall take into account any death of a woman during pregnancy, childbirth or within a period of 42 days after her termination, irrespective of the duration and location of any cause determined or aggravated by pregnancy or care that it has motivated, but neither accidental nor fortuitous. ${ }^{1}$
The deaths within the hospital are the deaths corresponding to this definition. They have occurred in the hospital space regardless of the service and regardless of the time between the time of the death of the time of admission. The maternal mortality ratio is the ratio of the number of intra-hospital maternal deaths for one year to the number of live births in the hospital during the corresponding year.

\section{Study Framework}

Our study took place in the maternity ward of the CHU of Borgou-Alibori which is a university center in Benin since 2015.

It is organized in 8 functional units, the unit of the Emergency, the unit of the Consultation, the unit of the delivery room which has 4 childbirth tables and an expansion room with 6 beds. The unit of the operating block which consists of two operating rooms, one of which is equipped. The resuscitation unit has 3 rooms with 12 beds.

The hospitalization unit, which has 6 rooms, including 3 categories, offering 34 beds, the vaccination unit and the ultrasound unit.

The medical staff is composed by 6 gynaecologistsobstetricians, 13 state midwives, 10 state nurses, 20 orderlies, 4 maintenance officers, 1 Secretary and 4 anaesthetists. The population of Borgou-Alibori is estimated at 1,124,294 inhabitants in 2013.

\section{Study Type and population}

This is a retrospective cross-sectional study with descriptive and analytic aim. It takes into account all the women who died in the maternity ward of the CHU of Borgou-Alibori Were included in present study all women died for obstetric causes. Are not included all those who died for non-obstetric cases and those with incomplete records.

\section{Data collection, processing and analysis}

The method used for data collection is documentary research. The analysis of the content by stripping is the technique used and the data collection tool is the stripping sheet.

Our data were processed using EPI-Info software Version 7.1.4.0 and SPSS 20. The results are presented in the form of tables and figures. Ethical consideration requires us to keep the confidentiality of the contents of the files.

\section{RESULTS}

Our results will focus on the evolution of the maternal mortality ratio from 2010 to 2014 at the maternity Hospital of the Borgou-Alibori, the demographic profile 
of the deceased women, the number of prenatal counselling, the mode of admission of the deceased women as well as the means of transportation and the causes of maternal death. The evolution of the maternal mortality ratio from 2010 to 2014 in the maternity ward of the CHU of Borgou-Alibori is represented by Table 1 .

Table 1: Distribution of deceased women per year at CHUD of Parakou.

\begin{tabular}{|lllll|}
\hline Year & Number & Number of childbirths & Ratio /100000 live childbirths & IC95\% \\
\hline 2010 & 17 & 1784 & 953 & $500-1400$ \\
\hline 2011 & 26 & 1990 & 1307 & $800-1800$ \\
\hline 2012 & 22 & 2215 & 993 & $600-1400$ \\
\hline 2013 & 22 & 1844 & 1193 & $700-1700$ \\
\hline 2014 & 26 & 1873 & 1388 & $800-1800$ \\
\hline Total & 113 & 9706 & 1164 & $900-1400$ \\
\hline
\end{tabular}

The socio-demographic profile of deceased women is shown in the table below.

Table 2: Distribution of deceased women according sociodemographic profile at the CHDU of Parakou.

\begin{tabular}{|lcc|}
\hline Variables & No., N=113 & Percentage \\
\hline Age in years & & \\
\hline $15-19$ & 15 & 13.3 \\
\hline $20-34$ & 80 & 70.8 \\
\hline $35-45$ & 18 & 15.9 \\
\hline Education level & & \\
\hline Non educated/Primary & 99 & 87.6 \\
\hline Secondary /university level & 14 & 12.4 \\
\hline Matrimonial status & & \\
\hline Single & 21 & 18.6 \\
\hline Married & 92 & 81.4 \\
\hline
\end{tabular}

Table 3: Distribution of deceased women according number of prenatal counselling performed in the course of pregnancy before death.

\begin{tabular}{|lll|}
\hline & No., $\mathbf{N}=113$ & Percentage \\
\hline 0 & 60 & 53.1 \\
\hline$[1 ; 3]$ & 36 & 31.9 \\
\hline$[4 ; 6]$ & 17 & 15.0 \\
\hline
\end{tabular}

Table 4: Distribution of deceased women according number of prenatal counselling performed in the course of pregnancy before death.

\begin{tabular}{|lll|}
\hline \multicolumn{2}{l}{ No. N=113 } & Percentage \\
\hline Admission modus & & \\
\hline Transferred & 78 & 69.0 \\
\hline Free admission & 35 & 31.0 \\
\hline Means of transport & & \\
\hline Medicated ambulance & 30 & 26.5 \\
\hline Non medicated ambulance & 83 & 73.5 \\
\hline
\end{tabular}

Table 3 indicates the deceaded women according to the number of pnenatal counselling performed in the course of the pregnancy before death. In Table 4, deceased women are divided according to the mode of admission and the means of transport. In Table 5, the distribution of deceased women according to the causes of maternal death.

Table 5: Distribution of deceased women according to the causes of maternal death at CHUD of Parakou.

\begin{tabular}{|lll|}
\hline $\begin{array}{ll}\text { Death causes } \\
\text { Directes causes }\end{array}$ & Number & Percentage \\
\hline Hemorrhage of $1^{\text {st }}$ term & 18 & 15.9 \\
\hline $\begin{array}{l}\text { Hemorrhage of } 2^{\text {nd }} \text { et } 3^{\text {rd }} \\
\text { term }\end{array}$ & 6 & 5.3 \\
\hline Postpartum hemorrhage & 30 & 26.5 \\
\hline Dystocia & 4 & 3.5 \\
\hline Eclampsia & 22 & 19.5 \\
\hline Infection & 11 & 9.8 \\
\hline Indirect causes & & \\
\hline Anemia & 9 & 8.0 \\
\hline OAP & 1 & 0.9 \\
\hline Insuffisance rénale & 1 & 0.9 \\
\hline Malaria & 5 & 4.3 \\
\hline HIV & 2 & 1.8 \\
\hline Drépanocytose & 3 & 2.7 \\
\hline Diabetes & 1 & 09 \\
\hline Total & 113 & 100 \\
\hline
\end{tabular}

\section{DISCUSSION}

It will focus on the evolution of the maternal mortality ratio from 2010 to 2014 in the maternity ward of the Borgou-Alibori, the demographic profile of the deceased women, the number of prenatal counselling, the mode of admission of the deceased women and the Means of transport and the causes of maternal death.

\section{The maternal mortality ratio}

At the maternity hospital of the Borgou-Alibori, the maternal mortality ratio in our study is 1164 deaths for 100,000 live births from 2010 to 2014 or 5 years. De 
Groof et al. in 1997, in a study on the importance of an indirect demographic method for estimating maternal mortality in Niger found a maternal mortality ratio of 700 deaths for 100,000 live births, which is lower than ours. ${ }^{5}$ Lawson et al. in 1998, in a study on maternal mortality in maternity at the National Hospital Centre in Ouagadougou (Burkina-Faso) found a maternal mortality ratio to 4110 maternal deaths for 100,000 live births. ${ }^{6}$ This ratio is higher than ours. This can be explained by the episodes of strike marked by a decrease in staff in our hospitals for the management of obstetric emergencies.

\section{Demographic profile of deceased women}

In our study, the age group of 20-34 years is represented by $70.8 \%$. This figure shows that maternal deaths occur especially among young women. ${ }^{7}$ A study conducted in Nigeria by Harrison showed that the maternal mortality rate was 7 times higher among women 15 years than those aged 20-34 years.

For Thiéba et al. the most represented age group is 20 to 34 years. These results are almost identical to ours. ${ }^{8}$ In our study $87.6 \%$ of women who died were non-academic or primary and $62.9 \%$ were non-academic. This result is consistent with that of Ouedraogo et al. in Burkina Faso who found that $57.2 \%$ of the women who died were uneducated. In fact, a high level of education makes it possible to understand the usefulness of the delivery of prenatal consultations. ${ }^{9}$

The present study reveals that $81.4 \%$ of women who have died are married women. On the other hand, MayiTsonga et al. found that $75 \%$ of the deceased women were single. ${ }^{10}$ This can be explained by early marriages.

\section{Prenatal counselling}

In the present study $53 \%$ of women who died did not have prenatal follow-up. This lack of EIC can be explained by socio-cultural factors that block the attendance of health centres by pregnant women, among which there is poverty and poor decision-making power of women

\section{The mode of admission}

In the present study, $69 \%$ of deceased women are referred. This situation was confirmed in a study by Mayi-Tsonga et al. which reported that of the maternal deaths 7 out of 10 cases are women evacuated or referred. ${ }^{10}$ This situation can be explained either by a poor organisation of the reference or a lack of communication between the health centres which refer to the maternity of University Hospital of Parakou.

\section{The means of transport}

The present study shows that $73.5 \%$ of the women who died had received unmedicated transport. This is similar to that of Horo et al., who noted an unhealthy transfer for most cases of maternal death. ${ }^{11}$

This is due to the lack of ambulance in our health training.

\section{Causes of maternal death}

\section{Direct Obstetric Causes}

In the present study, direct causes are: postpartum hemorrhage, eclampsia, risky abortions, infections, dystocia, GEU, placenta previa, HRP, uterine rupture. These direct causes account for $80.5 \%$ of maternal deaths. Our results are similar to those of Maria with a rate of $78 \%$. This high rate reflects the magnitude of the mortality problem and shows that direct obstetric causes remain the permanent cause of maternal death whose care must be urgent and systematic. ${ }^{12}$

\section{Indirect obstetric Causes}

Anaemia, Pao, renal failure, malaria, sickle cell anemia, diabetes and HIV represent the indirect causes in our study at a rate of $19.5 \%$. Similar to the WHO outcome with $20 \% .^{3}$ This non-negligible rate shows that indirect Causes require early detection, appropriate treatment and strict surveillance.

\section{CONCLUSION}

Maternal mortality continues to increase in the maternity ward of the Borgou-Alibori CHU. For the most part, women who have died are uneducated, married and aged 20 to 34 years. Emergency obstetric care is paramount in the management of obstetric emergencies and the causes of maternal deaths remain unchanged, these are direct and indirect obstetric causes.

Obstetric emergencies determine maternal deaths and the resurgence of maternal deaths is due to dysfunction in the non-availability of emergency obstetric care. For this reason, it is essential to strengthen the systems of audits of maternal deaths, to follow up the execution of the decisions of the audits and to make the retro information of the evacuees formal.

Funding: No funding sources Conflict of interest: None declared

Ethical approval: The study was approved by the Institutional Ethics Committee

\section{REFERENCES}

1. Organisation Mondiale de la Santé (OMS). International Statistical Classification of Diseases and Related Health Problems. InCIM-10: International Statistical Classification of Diseases and Related Health Problems. OMS. 1993;2. 
2. World Health Organization (WHO). "Maternal mortality", fact sheet, $n{ }^{\circ} 348$ Pedagogical sheet Ined.

3. World Health Organization (WHO). Maternal mortality. Media Center. Memorandum No. 348, May 2014

4. WHO, UNICEF, UNFPA, WORLD BANK. Maternal death ratio (Estimate per 100,000 live births). 2015.

5. De Groof D, Issoufou Y. Importance of an indirect demographic method for estimating maternal mortality: The experience of Niger. Med Black Afr. 1997; 44(4):192-94.

6. Lankouande J, Ouedraogo $\mathrm{CH}$, Toure B, Ouedraogo A, Dao B, Kone B. Maternal mortality at the maternity hospital of the national hospital of Ouagadougou (Burkina-Faso): about 123 cases collected in 1995. Med Black Afr. 1998.45(3):18790.

7. Harrison KA. Child-bearning, health and social priorities. A survey of 22774 . Consecutive hospital births in Zaria, Northern Nigeria. Br J Obstet Gynecol. 1985;5:119

8. Thiéba B, Ouédraogo PA, Akotionga M, Koné B. Reference and counter reference system of obstetric gynecological emergencies maternity of the city of Ouagadougou, Burkina Faso. Abstract of the 7th
SAGO congress, SOMAGO II Bamako. 2003: 21920.

9. Ouédraogo C, Testa J, Sondo B, Koné B. Analysis of risk factors for severe morbidity in Ouagadougou, Burkina Faso. Application to prenatal consultation card. Med Black Afr. 2001; 48(10):402-10.

10. Mayi-Tsonga S, Oksana L, Diallo T, Metogho M, Ndombi I, Mendome G et al. Study on maternal deaths at the hospital center of Libreville (Gabon). Medicine of Black Africa. August / September 2010; 57 (8-9): 425-31.

11. Horo A, Toure-Ecra F, Mouhamed F, Adjoussou S, Koné M. Malfunctioning and maternal mortality. Analysis of 35 cases at the maternity hospital of Yopougon University Hospital (Abidjan, Côte d'Ivoire). Medicine of Black Africa 2008; 55(8-9): 449-53.

12. Maria R. Maternal Mortality: Avoidable Obstetric Complications. J Gynecol Obstet Reprod Biol. $2001.30(6): 60$.

Cite this article as: Adisso S, Agbossaga GE T, Ntakwinja M, Pandey A. What can a mother die of at the Parakou University Hospital Center in Africa? Int J Reprod Contracept Obstet Gynecol 2018;7: 1677-81. 